\title{
Laquinimod prevents cuprizone-induced demyelination independent of Toll-like receptor signaling \\ OPEN
}

Nadine Kramann, $\mathrm{PhD}^{*}$

Lena Menken*

Liat Hayardeny, $\mathrm{PhD}$

Uwe-Karsten Hanisch,

$\mathrm{PhD} \dagger$

Wolfgang Brück, MD

Correspondence to

Dr. Kramann:

nadine.kramann@medizin.uni-

goettingen.de

\section{ABSTRACT}

Objective: To test whether Toll-like receptor (TLR) signaling plays a key role for reduced nuclear factor B (NF-кB) activation after laquinimod treatment in the model of cuprizone-induced demyelination, oligodendrocyte apoptosis, inflammation, and axonal damage.

Methods: Ten-week-old C57BL/6J, TLR4 ${ }^{-1}$, and MyD88--- mice received 0.25\% cuprizone for 6 weeks and were treated daily with $25 \mathrm{mg} / \mathrm{kg}$ laquinimod or vehicle. After 6 weeks of demyelination, extent of demyelination, oligodendrocyte density, microglia infiltration, and axonal damage were analyzed in the corpus callosum. Additionally, we analyzed primary mouse astrocytes from

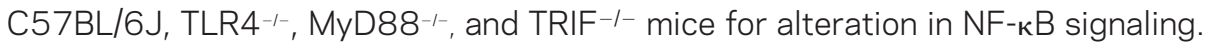

Results: Vehicle-treated controls from C57BL/6J, TLR4-1-, and MyD88 ${ }^{-1-}$ mice displayed extensive callosal demyelination as well as microglial activation. In contrast, mice treated with $25 \mathrm{mg} / \mathrm{kg}$ laquinimod showed mainly intact callosal myelin. The demyelination score was significantly higher in all untreated mice compared to mice treated with laquinimod. There were significantly fewer APP-positive axonal spheroids, Mac3-positive macrophages/microglia, and less oligodendrocyte apoptosis in the corpus callosum of laquinimod-treated mice in comparison to untreated controls. Stimulated primary mouse astrocytes from laquinimod-treated groups show reduced NF-кB activation compared to vehicle-treated controls.

Conclusions: Our results confirm that laquinimod prevents demyelination in the cuprizone mouse model for multiple sclerosis via downregulation of NF-кB activation. This laquinimod effect, however, does not involve upstream Toll-like receptor signaling. Neurol Neuroimmunol Neuroinflamm 2016;3:e233; doi: 10.1212/NXI.0000000000000233

\section{GLOSSARY}

APP $=$ amyloid precursor protein; CDP = confirmed disability progression; IFN- $\boldsymbol{\gamma}=$ interferon- $\boldsymbol{\gamma}$ IL-1 $\boldsymbol{\beta}=$ interleukin- $1 \beta$; LFBPAS = Luxol fast blue-periodic acid-Schiff; LPS = lipopolysaccharide; $\mathbf{M S}=$ multiple sclerosis; $\mathbf{M y D 8 8}=$ myeloid differentiation primary response 88; NF-кB = nuclear factor B; TIR = Toll-IL-1 receptor; TLR = Toll-like receptor; TRIF = Toll-IL-1 receptor domain containing adapter inducing interferon- $\gamma ; \mathbf{W T}=$ wild-type.

Multiple sclerosis (MS) is the most common cause of nontraumatic disability in young adults. MS is a chronic inflammatory demyelinating disease of the CNS causing focal lesions in white and gray matter, ${ }^{1,2}$ which are pathologically characterized by inflammation, demyelination, microglial activation, astrogliosis, and axonal injury. Activation of the nuclear factor B (NF- $\mathrm{B}$ ) in MS brains has been detected in oligodendrocytes, astrocytes, microglia, and infiltrating macrophages in or close to CNS lesions. ${ }^{3,4}$

Laquinimod is an oral immunomodulator in clinical development for the treatment of relapsing-remitting MS and progressive $\mathrm{MS}^{5,6}$ that is thought to mitigate both the inflammatory and the neurodegenerative aspects of MS. It is a small molecule passively entering the CNS, ${ }^{7}$ which has been found to inhibit clinical signs of experimental autoimmune encephalomyelitis,

\footnotetext{
*These authors contributed equally to this work.

$\dagger$ Deceased.

From the Institute of Neuropathology (N.K., L.M., U.-K.H., W.B.), University Medical Center Göttingen, Germany; and Teva Pharmaceutical Industries (L.H.), Netanya, Israel.

Funding information and disclosures are provided at the end of the article. Go to Neurology.org/nn for full disclosure forms. The Article Processing Charge was paid by the authors.

This is an open access article distributed under the terms of the Creative Commons Attribution-NonCommercial-NoDerivatives License 4.0 (CC BY-NC-ND), which permits downloading and sharing the work provided it is properly cited. The work cannot be changed in any way or used commercially.
} 
the established autoimmune animal model of MS. ${ }^{89}$ Additionally, laquinimod has shown CNS-protective effects in cuprizone-induced demyelination, another experimental model of MS. ${ }^{10}$

Toll-like receptor (TLR) stimulation is a major and potent inducer upstream of the NF-кB signaling pathway. TLRs recruit adapter proteins with Toll-IL-1 receptor (TIR) domain containing adapter myeloid differentiation primary response $88(\mathrm{MyD} 88)$ and the adapter molecule TIR domain containing adapter inducing interferon- $\gamma$ (TRIF), ${ }^{11}$ resulting in downstream activation of NF- $\mathrm{KB}$ (figure 1). ${ }^{10,12}$ To address the question whether TLR signaling is essential for downstream activation of NF- $\mathrm{B}$, we studied the effect of laquinimod treatment in transgenic mice and primary

Figure 1 Activation of nuclear factor B (NF-кB) through Toll-like receptor (TLR) signaling

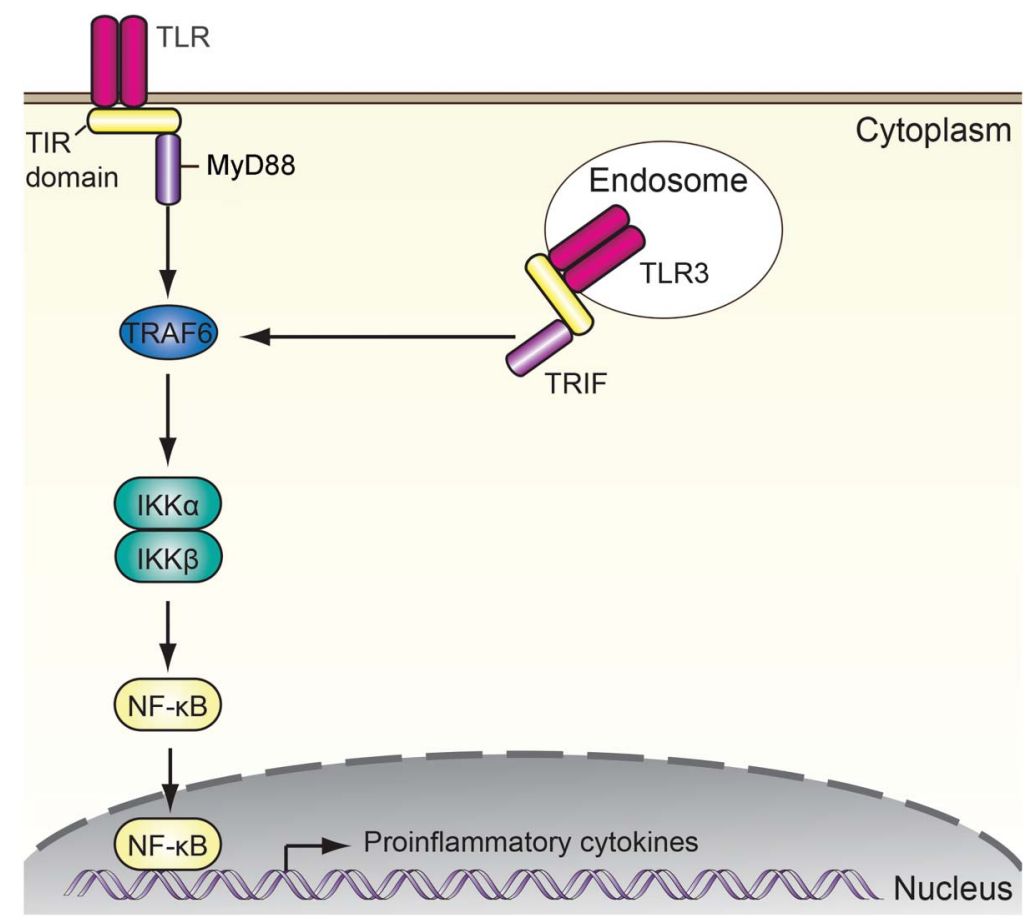

At the cell surface, TLRs bind to their respective ligands. TLR3 is localized at endosomes, where they sense host-derived or microbial nucleic acids. TLR4 can be localized at both the plasma membrane and the endosomes. After ligand-induced dimerization of receptors, TLR signaling is initiated. Afterwards, Toll-IL-1 receptor (TIR) domain-containing adaptor proteins are engaged: either myeloid differentiation primary response 88 (MyD88) or Toll-IL-1 receptor domain containing adapter inducing interferon- $\gamma$ (TRIF), leading to stimulation of downstream signaling pathways involving tumor necrosis factor receptor-associated factor (TRAF). One important transcription factor downstream of TLR signaling is NF-кB. In resting conditions, NF-кB dimers in the cytoplasm are bound to their inhibitor of $\kappa \mathrm{B}\left(\mathrm{I}_{\kappa} \mathrm{B}\right)$ proteins. After activation, the $I_{\kappa} B$ kinase $(\mathrm{IKK})$ complex phosphorylates $I_{\kappa} B$ proteins, leading to their polyubiquitinilation and degradation by the proteasome. NF- $\mathrm{B}$ is then released from its inhibitor, translocates to the nucleus, and exerts its transcriptional activity. A major consequence of TLR signaling is the induction of proinflammatory cytokines. mouse astrocytes lacking important TLR signaling components.

METHODS Laquinimod. Laquinimod (originally ABR215062) (RLB\#054 M0004) was synthesized at Teva Pharmaceutical Industries (Petah Tikva, Israel). Mice were treated daily with $25 \mathrm{mg} / \mathrm{kg}$ laquinimod administered by oral gavage from the beginning of the cuprizone feeding. This dose has previously been shown to protect mice from cuprizoneinduced demyelination. ${ }^{10}$ Cuprizone and laquinimod treatment was given for 6 weeks. Control mice received water as vehicle. In vitro, cell cultures were treated with $250 \mathrm{~nm}$ laquinimod or with vehicle as described below.

Animals. Transgenic TLR4 ${ }^{-1-}, \mathrm{MyD} 88^{-1-}$ mice were obtained from the animal facility at the University of Göttingen or from The Jackson Laboratory (Bar Harbor, ME). TRIF ${ }^{\text {lps2 }}$ mice were provided by Bruce Beutler, La Jolla, California. The latter mice have a frameshift error mutation in the C-terminus of TRIF, resulting in abrogated TRIF function, ${ }^{13}$ and homozygous mice are from now on referred to TRIF $^{-1-}$. Wild-type (WT) C57BL/6 mice were obtained from Charles River Laboratories (Sulzfeld, Germany). All animal experimentation was carried out in accordance with the European Council Directive of September 2010 (2010/63/EU) and was approved by the Lower Saxony Federal State Office for Consumer Protection and Food Safety, Germany.

Cuprizone treatment. Toxic demyelination was induced by cuprizone (oxalic bis[cyclohexylidenehydrazide]; Sigma-Aldrich,

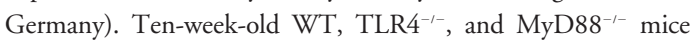
received a cuprizone diet of $0.25 \%$ cuprizone ad libitum for 6 weeks to study demyelination of the corpus callosum. Body weights of mice were controlled once weekly.

Histopathology. After 6 weeks of cuprizone diet, mice were perfused with $4 \%$ paraformaldehyde. Brains were postfixed and embedded in paraffin. To determine demyelination, histologic evaluation was performed on sections stained with Luxol fast blue-periodic acid-Schiff (LFB-PAS). Immunohistochemistry was performed with primary antibodies against activated microglia (Mac-3, 1:200, clone M3/84; BD Pharmingen, San Jose, CA), oligodendrocytes (p25, 1:500, clone EPR3316; Abcam, Cambridge, UK), ${ }^{14}$ and acutely damaged axons (amyloid precursor protein [APP], 1:2,000, clone 22C11; Millipore, Billerica, MA).

Cell culture and laquinimod treatment. Primary astrocytic cultures from newborn mice were prepared as described previously. ${ }^{10}$ Astrocytic cell cultures were preincubated with $250 \mathrm{nM}$ laquinimod for 2 hours. Afterwards, they were treated with the combination of $10 \mathrm{ng} / \mathrm{mL}$ interleukin- $1 \beta$ (IL-1 $\beta$ ) and $10 \mathrm{ng} / \mathrm{mL}$ interferon- $\gamma($ IFN- $\gamma$ ) for 1 hour in order to perform the NF- $\mathrm{KB}$ reporter assay in the absence and presence of laquinimod.

Morphometry and data acquisition. Demyelination of the corpus callosum was assessed on LFB-PAS-stained sections using a semiquantitative scoring system as previously described $^{10}$ : no demyelination (0), $<33 \%$ demyelination (1), $33 \%-66 \%$ demyelination (2), $>66 \%$ demyelination (3). The densities of p25-positive oligodendrocytes, Mac-3-positive cells, and APP-positive axons were quantified.

Statistical analysis. Statistical analysis was carried out using GraphPadPrism (version 5.01, GraphPad Software; La Jolla, $\mathrm{CA}$ ). Histologic differences between laquinimod-treated and control mice were analyzed using one-way analysis of variance followed by Tukey multiple comparison test for parametric and 
Dunn multiple comparison test for nonparametric data. Statistical significance was defined as $p<0.05$.

RESULTS Laquinimod reduces cuprizone-induced demyelination and oligodendrocyte loss. Feeding of cuprizone induces subsequent demyelination and oligodendrocyte apoptosis. To test whether the protective effect of laquinimod is TLR-dependent, WT, $\mathrm{TLR}^{-1-}$, and MyD88 ${ }^{-1-}$ mice received a daily dose of $25 \mathrm{mg} / \mathrm{kg}$ laquinimod during 6 weeks of cuprizoneinduced demyelination. In each group, demyelination was evaluated in the corpus callosum. Untreated WT, $\mathrm{TLR}^{-1-}$, and $\mathrm{MyD} 88^{-/-}$mice displayed extensive callosal demyelination (figure 2, A, C, and E), whereas WT, $\mathrm{TLR}^{--}{ }^{-}$, and $\mathrm{MyD} 88^{-1-}$ mice treated with $25 \mathrm{mg} / \mathrm{kg}$ laquinimod showed mainly intact callosal myelin with only minor signs of demyelination (figure 2, B, D, and E). Demyelination scores were higher in vehicle-treated mice (WT: $2.38 \pm 0.18$, $\mathrm{n}=10 ; \mathrm{MyD}^{-1-}: 2.00 \pm 0.18, \mathrm{n}=8 ; \mathrm{TLR}^{-1-}$ : $3.00 \pm 0.10, \mathrm{n}=7)$ than in mice treated with laquinimod (WT: $0.69 \pm 0.09, \mathrm{n}=9, p<0.05$; MyD88 $8^{-1-}: 0.08 \pm 0.07, \mathrm{n}=6, p<0.001 ; \mathrm{TLR}^{-1-}$ : $0.86 \pm 0.09, \mathrm{n}=7, p<0.05$ ) (figure $2 \mathrm{E}$ ).

Cuprizone induces oligodendroglial apoptosis. To assess if the effect of laquinimod on oligodendroglia

\section{Figure 2 Laquinimod (LAQ) reduces demyelination and oligodendrocyte loss after 6 weeks of cuprizone}
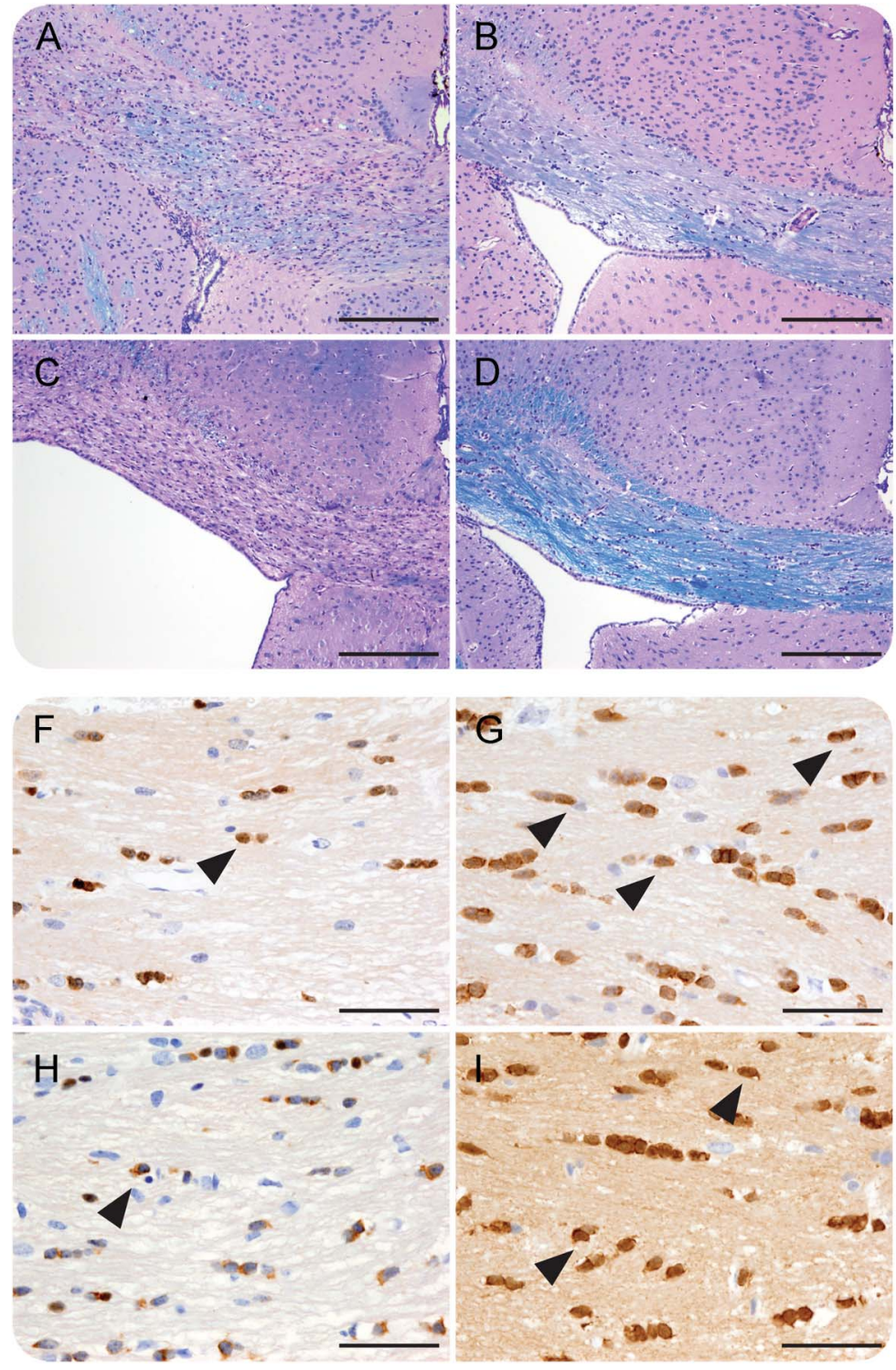
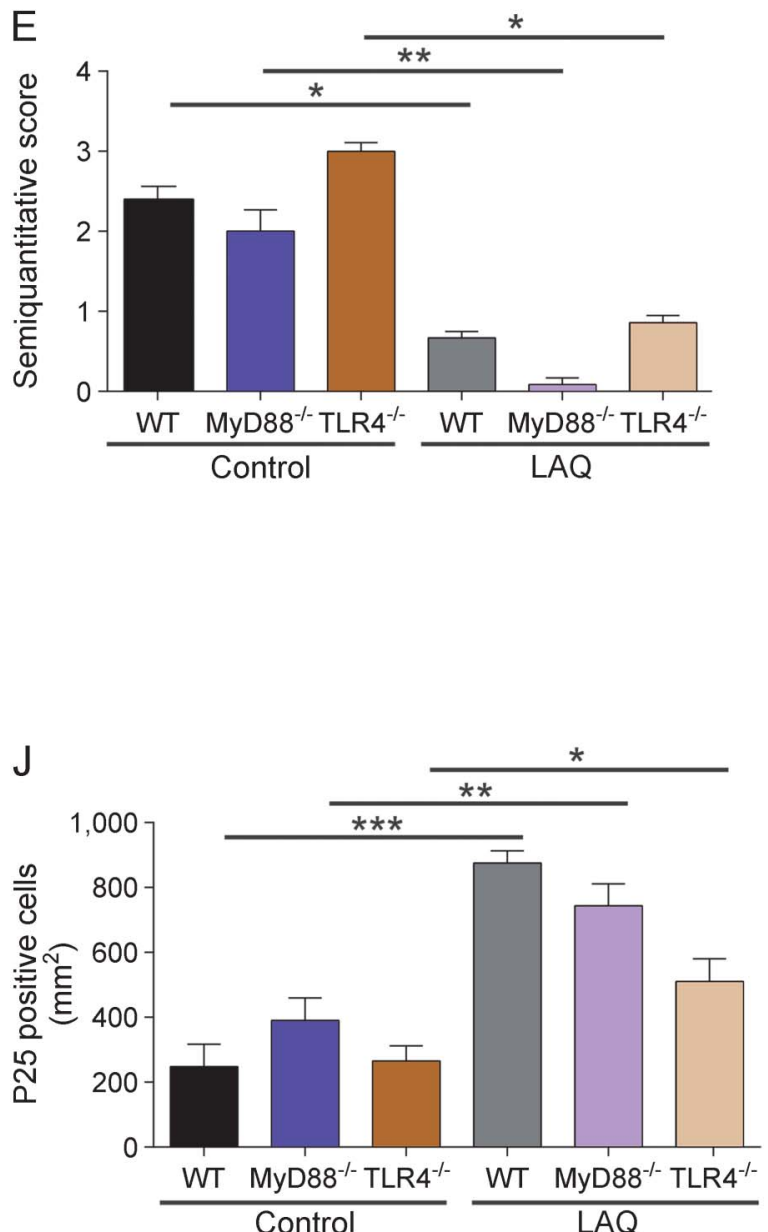

Demyelination is extensive in the corpus callosum of vehicle-treated wild-type (WT) mice (A) and myeloid differentiation primary response 88 (MyD88 ${ }^{-1-}$ ) mice (C) compared to moderate demyelination after treatment with laquinimod in WT (B) and MyD88-1- mice (D). In all groups, mice treated with laquinimod displayed lower demyelination scores than vehicle-treated controls (E). Staining for p25+ oligodendrocytes revealed reduced oligodendrocyte numbers in vehicle-treated WT $(F)$ and MyD88 ${ }^{-1-}(\mathrm{H})$ mice compared to mice treated with laquinimod $(\mathrm{G}, \mathrm{I})$. In all groups, mice treated with laquinimod displayed higher p25+ oligodendrocyte numbers than vehicle-treated controls (J) (scale bars $200 \mu \mathrm{m}$ [A-D], $50 \mu \mathrm{m}[\mathrm{F}-\mathrm{I}])(* \mathrm{p}<0.05 ; * * \mathrm{p}<0.01$; ***p $<0.005$ with Tukey multiple comparison). Black arrowheads mark exemplary p25+ oligodendrocytes. TLR $=$ Toll-like receptor. 
density after cuprizone challenge is dependent on TLR signaling, we analyzed WT (figure 2, G and I), $\mathrm{TLR}^{-{ }^{--}}$, and $\mathrm{MyD}^{-8^{--}}$(figure 2, $\mathrm{F}$ and $\mathrm{H}$ ) mice treated with laquinimod (figure $2, \mathrm{~B}$ and $\mathrm{D}$ ) or vehicle (figure 2, A and C). After 6 weeks of cuprizone, mice treated with laquinimod show higher p25-positive oligodendrocyte numbers (WT: $875.59 \pm 33.42, \mathrm{n}=9$, $p<0.001 ; \mathrm{MyD}^{-1-}: 743.57 \pm 68.03, \mathrm{n}=6, p<$ 0.005 TLR4 $\left.^{-1-}: 510.36 \pm 70.38, \mathrm{n}=6, p<0.05\right)$ compared to vehicle-treated controls (WT: $247.74 \pm$

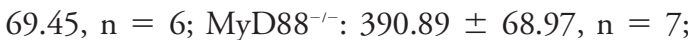
TLR4 $^{-1-}: 265.44 \pm 56.79, \mathrm{n}=12$ ) (figure 2J).
Laquinimod reduces microglia activation and acute axonal damage. Accumulation of microglia was investigated by Mac-3 staining. Microglia were evaluated within the corpus callosum of WT (figure 3, A and $\mathrm{B}), \mathrm{TLR}^{-1-}$, and $\mathrm{MyD} 88^{-- \text {(figure } 3, \mathrm{C} \text { and D) mice }}$ treated with laquinimod (figure $3, \mathrm{~B}$ and $\mathrm{D}$ ) or vehicle (figure, $3 \mathrm{~A}$ and $\mathrm{C}$ ). The microglia density was reduced during laquinimod treatment (WT: $170.19 \pm 27.92$, $\mathrm{n}=9 ;$ MyD88 $^{--}: 102.14 \pm 33.64, \mathrm{n}=5 ;$ TLR $^{-1-}$ : $279.08 \pm 55.75, \mathrm{n}=7)$ compared to vehicle-treated controls (WT: $990.33 \pm 94.13, \mathrm{n}=10, p<0.001$; MyD88 ${ }^{-1}: 465.45 \pm 50.74, \mathrm{n}=7, p<0.05$;

Figure 3 Laquinimod (LAQ) reduces microglia infiltration and acute axonal damage after 6 weeks of cuprizone
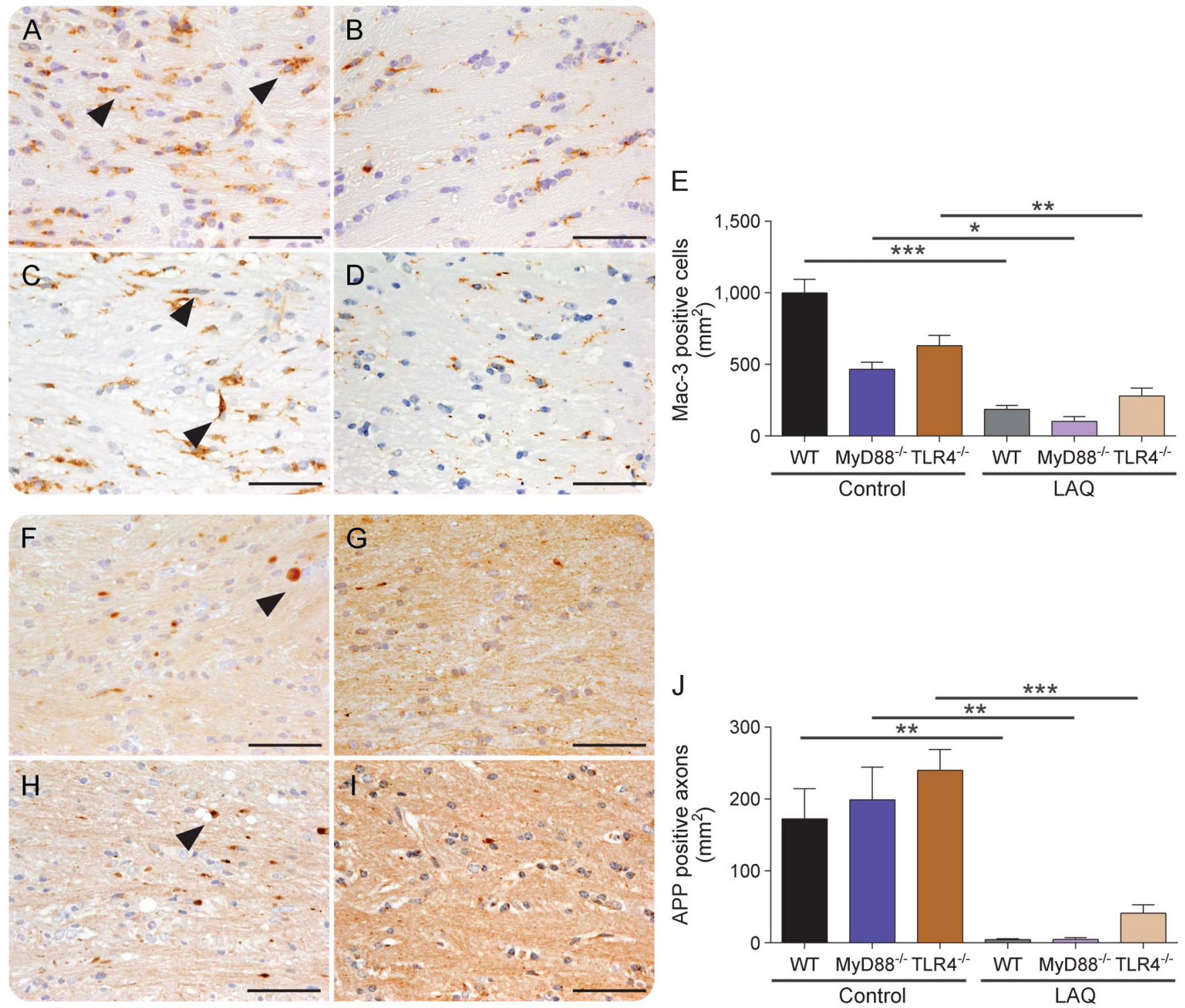

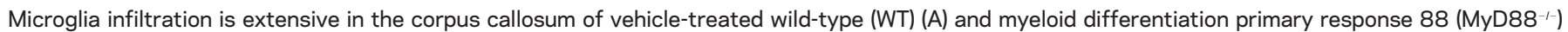

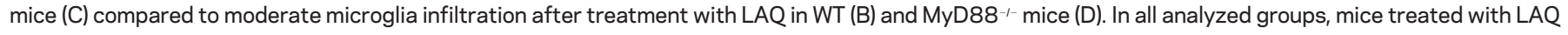

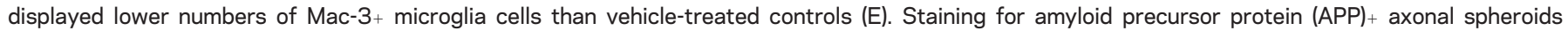

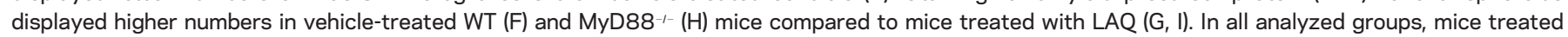

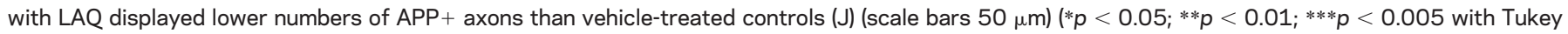
multiple comparison). Black arrowheads mark exemplary Mac-3+ microglia and APP + axonal spheroids. TLR $=$ Toll-like receptor. 
Figure 4 Laquinimod downmodulates astrocytic nuclear factor B (NF-кB) activation in vitro

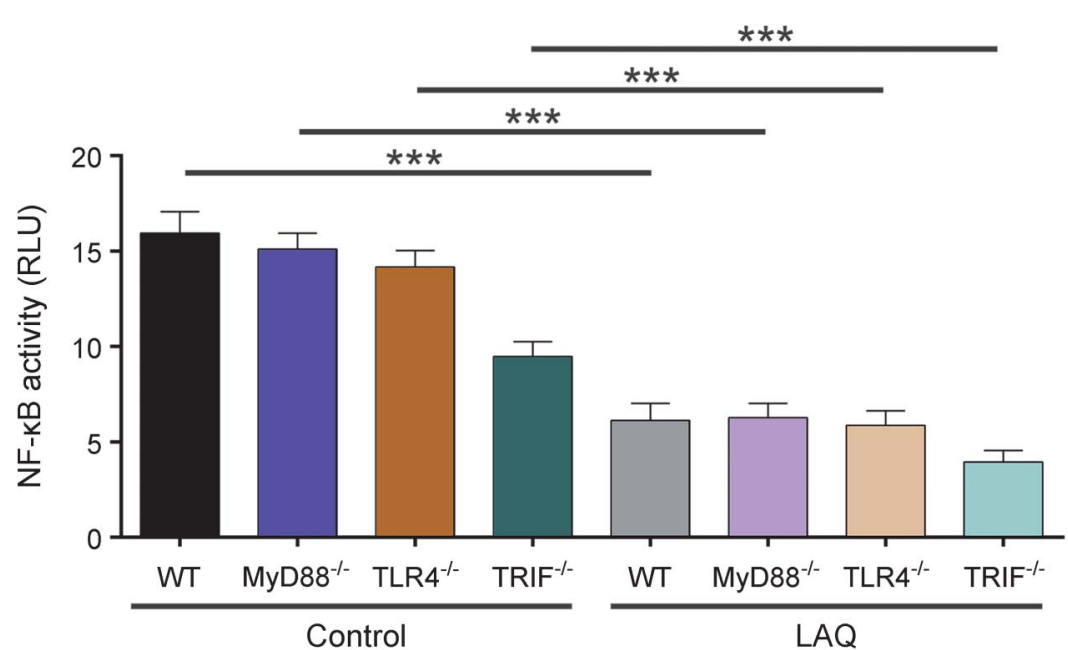

Pretreatment with laquinimod reduces NF-кB activity in stimulated primary mouse astrocytes. Transfected cells were pretreated with $250 \mathrm{nM}$ laquinimod and stimulated with interleukin-1 $\beta$ and interferon- $\gamma$. NF-кB activity was measured luminometrically (relative light units [RLU]). In all groups, pretreatment with laquinimod reduces NF-кB activation after cytokine stimulation (all groups were normalized to unstimulated controls) (***p $<0.005$ ). MyD88 = myeloid differentiation primary response $88 ;$ TLR $=$ Toll-like receptor; TRIF $=$ TollIL-1 receptor domain containing adapter inducing interferon- $\gamma$; WT $=$ wild-type.

$\left.\mathrm{TLR}^{-1-}: 517.06 \pm 73.11, \mathrm{n}=13, p<0.005\right)$ (figure 3E).

To determine the effect of laquinimod on axonal integrity, we analyzed acutely damaged axons characterized by swelling and accumulation of the APP. APP-positive axons were evaluated within the corpus callosum of WT (figure 3, F and G), TLR4 $4^{-1-}$, and

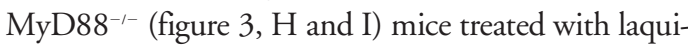
nimod (figure 3, G and I) or vehicle (figure 3, F and $\mathrm{H})$. There was a reduction of acute axonal damage under laquinimod (WT: $4.45 \pm 1.10, \mathrm{n}=9$; MyD88 $8^{-1-}: 4.64 \pm 2.40, \mathrm{n}=6$; TLR4 $^{-1-}: 41.00 \pm$ $11.99, \mathrm{n}=7)$ compared to vehicle-treated controls (WT: $172.36 \pm 42.09, \mathrm{n}=8, p<0.005$; MyD88 $^{-1}: 198.93 \pm 45.35, \mathrm{n}=8, p<0.005$; TLR $\left.^{-1-}: 239.87 \pm 29.07, \mathrm{n}=13, p<0.001\right)$ (figure $3 \mathrm{~J}$ ).

Laquinimod downmodulates astrocytic NF- $\mathrm{B}$ activation in vitro. Since our previous investigations showed a protective effect of laquinimod through regulation of astrocytic NF-кB activation, we further analyzed the effect of laquinimod treatment in primary astrocytes of WT and TLR signaling deficient mice.

To directly assess the in vitro effect of laquinimod on astrocytic NF- $\mathrm{KB}$ activity, we stimulated isolated mouse astrocytes with a combination of IL-1 $\beta$ and IFN- $\gamma$. We examined NF-кB activation with and without laquinimod pretreatment. Without laquinimod exposure, the cytokine treatments increased $\mathrm{NF}-\mathrm{KB}$ activation compared to unstimulated controls (all groups were normalized to unstimulated controls). The pretreatment with laquinimod reduced the stimulation-induced NF- $\mathrm{BB}$ activation (WT: $6.12 \pm 0.89 ; \mathrm{MyD}^{2} 8^{-1-}: 6.28 \pm 0.75$;LR $^{{ }^{-1-}}$ : $5.87 \pm 0.77$ TRIF $\left.^{-1-}: 3.94 \pm 0.62\right)$ compared to vehicle-treated controls (WT: $15.94 \pm 1.13$;

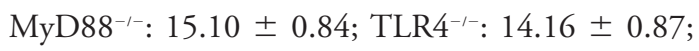
$\left.\mathrm{TRIF}^{-1-}: 9.48 \pm 0.77\right)(\mathrm{n}=3, p<0.005)($ figure 4$)$ in all analyzed mouse strains.

DISCUSSION Laquinimod is a new oral immunomodulator that has demonstrated in 2 phase III, placebo-controlled studies (Assessment of Oral Laquinimod in Preventing Progression in Multiple Sclerosis [ALLEGRO] and A phase III Trial of Niraparib Versus Physician's Choice in HER2 Negative, Germline BRCA Mutation-positive Breast Cancer Patients [BRAVO]) that $0.6 \mathrm{mg}$ laquinimod daily was associated with a $34 \%$ reduction in 3-month confirmed disability progression (CDP) and a $46 \%$ reduction in 6-month CDP. The positive effect on CDP is disproportionately larger than it would be predicted by the effect on relapse rate reduction. These clinical studies suggested a more extensive direct CNS protective effect of laquinimod than peripheral immunomodulation. This hypothesis was confirmed in previous experimental studies identifying astrocytes and microglial cells as the main target of laquinimod in the CNS and NF-kB downregulation as one of the major mechanisms of action. Here we show that the effect of laquinimod is independent of TLR signaling, which is one of the major pathways leading to downstream NF-кB activation.

It was recently shown that pretreatment of lipopolysaccharide (LPS)-activated human microglia with laquinimod regulates proinflammatory and antiinflammatory gene expression through TLR signaling in vitro. Reduced activation of human microglia after pretreatment with laquinimod for 24 hours was observed. In this study, laquinimod affected the activation of human microglia by TLR2 and TLR4 signaling in vitro. ${ }^{15}$ Therefore, we investigated whether there is a relationship between reduced NF- $\mathrm{kB}$ activation after laquinimod treatment and the TLR signaling pathway in vivo and in vitro. NF- $\mathrm{KB}$ can be activated by both MyD88-and TRIF-dependent pathways. ${ }^{16}$ MyD88deficient macrophages and embryonic fibroblasts fail to produce inflammatory cytokines and in these cells NF$\mathrm{KB}$ activation is delayed in response to LPS. ${ }^{17}$ TRIFdeficient cells show reduced production of inflammatory cytokines but early NF- $\mathrm{\kappa B}$ activation. ${ }^{18}$ These data indicate that both MyD88-and TRIF-dependent pathways are required for production of inflammatory cytokines. All TLRs are able to activate NF- $\mathrm{B}$ through the MyD88-dependent or TRIF-dependent pathways or 
both. ${ }^{16}$ However, a complete loss of NF- $\mathrm{B}$ activation in the absence of MyD88 and TRIF is observed in response to LPS indicating that TRIF-dependent pathways control late phase NF- $\mathrm{KB}$ activation. ${ }^{18}$ In contrast to laquinimod, other medications used for the treatment of MS have been shown to depend at least partly on TLR signaling. Glatiramer acetate effects on innate immune cells are blocked by TRIF deficiency; however, its effects were independent of MyD88 and NF-кB. ${ }^{19}$ The different and distinct mechanisms of action of these 2 compounds makes them reasonable candidates for future combination treatment approaches in MS.

We investigated TLR4-deficient and MyD88deficient mice in vivo and TLR4-deficient, MyD88deficient, and TRIF-deficient astrocytes in vitro. This is the first study excluding the effect of TLR signaling and its downstream effector molecules (MyD88 and TRIF) to play a role in reduced NF- $\kappa \mathrm{B}$ activation after laquinimod treatment. Feeding the copper chelator cuprizone leads to toxic demyelination in the brain of mice. Cuprizone induces oligodendroglial apoptosis and subsequent demyelination, which is not characterized by inflammation or blood-brain barrier breakdown. ${ }^{20}$ Laquinimod treatment significantly reduced demyelination after 6 weeks of cuprizone. Mice treated with laquinimod showed mainly intact myelin compared to almost complete demyelination in untreated controls. The effect was further associated with a reduced oligodendrocyte loss. Acute axonal damage was almost absent and reduced microglia infiltration was observed. In our previous study, we showed that these effects in WT mice were associated with reduced astrocytic NF- $\mathrm{B}$ activation in vivo, indicated by reduced nuclear $\mathrm{p} 65$ translocation in callosal astrocytes, exactly paralleling the in vitro studies. ${ }^{10}$ Mice with TLR signaling deficiency showed the same protective effect of laquinimod. In line with our in vivo studies, we found no profound effect in the lack of TLR signaling on NF- $\kappa \mathrm{B}$ activation after stimulation. All groups of stimulated primary mouse astrocytes showed reduced NF- $\kappa \mathrm{B}$ activation after treatment with laquinimod independent of TLR signaling.

Taken together, these experiments suggest that intact TLR signaling is not necessary for the protective effect of laquinimod on cuprizone-induced demyelination in vivo and in primary mouse astrocytes in vitro.

\section{AUTHOR CONTRIBUTIONS}

Nadine Kramann: design or conceptualization of the study, analysis or interpretation of the data, drafting the manuscript. Lena Menken: analysis or interpretation of the data, drafting the manuscript. Liat Hayardeny: design or conceptualization of the study, revising the manuscript for intellectual content. Uwe-Karsten Hanisch: design or conceptualization of the study. Wolfgang Brück: design or conceptualization of the study, revising the manuscript for intellectual content.

\section{ACKNOWLEDGMENT}

The authors thank Mareike Gloth for expert technical assistance.

\section{STUDY FUNDING}

No targeted funding.

\section{DISCLOSURE}

N. Kramann received travel funding and research support from Teva Pharmaceuticals. L. Menken received research support from Teva Pharmaceuticals. Liat Hayardeny is employed by and holds stock or stock options in Teva Pharmaceuticals. Uwe-Karsten Hanisch is deceased. W. Brück served on the advisory board for Genzyme, Novartis, Biogen, and Teva Pharmaceuticals; received speaker honoraria from Teva, Sanofi, Genzyme, Novartis, Merck-Serono, Biogen, and Bayer; is on the editorial board for Acta Neuropathologica, Therapeutic Advances in Neurological Disorders, Multiple Sclerosis International, and Neuropathology and Applied Neurobiology; received research support from Teva, Novartis, Bigoen, Genzyme, German Research Foundation, German Ministry for Science and Education, and Tschira Foundation; and served as an expert witness for Teva. Go to Neurology.org/nn for full disclosure forms.

Received December 16, 2015. Accepted in final form March 24, 2016.

\section{REFERENCES}

1. Kieseier BC, Stuve O. A critical appraisal of treatment decisions in multiple sclerosis: old versus new. Nat Rev Neurol 2011;7:255-262.

2. Stadelmann C, Wegner C, Bruck W. Inflammation, demyelination, and degeneration: recent insights from MS pathology. Biochim Biophys Acta 2011;1812: 275-282.

3. Gveric D, Kaltschmidt C, Cuzner ML, Newcombe J. Transcription factor NF-kappaB and inhibitor I kappaBalpha are localized in macrophages in active multiple sclerosis lesions. J Neuropathol Exp Neurol 1998;57: $168-178$.

4. Bonetti B, Stegagno C, Cannella B, Rizzuto N, Moretto G, Raine CS. Activation of NF-kappaB and c-jun transcription factors in multiple sclerosis lesions. Implications for oligodendrocyte pathology. Am J Pathol 1999;155:1433-1438.

5. Comi G, Jeffery D, Kappos L, et al. Placebo-controlled trial of oral laquinimod for multiple sclerosis. N Engl J Med 2012;366:1000-1009.

6. Vollmer TL, Wynn DR, Alam MS, Valdes J. A phase 2, 24-week, randomized, placebo-controlled, double-blind study examining the efficacy and safety of an antiinterleukin-12 and -23 monoclonal antibody in patients with relapsing-remitting or secondary progressive multiple sclerosis. Mult Scler 2011;17:181-191.

7. Bruck W, Wegner C. Insight into the mechanism of laquinimod action. J Neurol Sci 2011;306:173-179.

8. Brunmark C, Runstrom A, Ohlsson L, et al. The new orally active immunoregulator laquinimod (ABR-215062) effectively inhibits development and relapses of experimental autoimmune encephalomyelitis. J Neuroimmunol 2002; 130:163-172.

9. Yang JS, Xu LY, Xiao BG, Hedlund G, Link H. Laquinimod (ABR-215062) suppresses the development of experimental autoimmune encephalomyelitis, modulates the Th1/Th2 balance and induces the Th3 cytokine TGF-beta in Lewis rats. J Neuroimmunol 2004; 156:3-9.

10. Bruck W, Pfortner R, Pham T, et al. Reduced astrocytic NF-kappaB activation by laquinimod protects from cuprizone-induced demyelination. Acta Neuropathol 2012;124:411-424.

11. Akira S, Takeda K. Toll-like receptor signalling. Nat Rev Immunol 2004;4:499-511. 
12. Redaelli C, Gaffarogullari EC, Brune M, et al. Toxicity of teriflunomide in aryl hydrocarbon receptor deficient mice. Biochem Pharmacol 2015;98:484-492.

13. Hoebe K, Janssen EM, Kim SO, et al. Upregulation of costimulatory molecules induced by lipopolysaccharide and double-stranded RNA occurs by Trif-dependent and Trif-independent pathways. Nat Immunol 2003;4: 1223-1229.

14. Höftberger R, Fink $S$, Aboul-Enein F, et al. Tubulin polymerization promoting protein (TPPP/p25) as a marker for oligodendroglial changes in multiple sclerosis. Glia 2010; 58:1847-1857.

15. Mishra MK, Wang J, Keough MB, et al. Laquinimod reduces neuroaxonal injury through inhibiting microglial activation. Ann Clin Transl Neurol 2014;1:409-422.
16. Kawai T, Akira S. Signaling to NF-kappaB by Toll-like receptors. Trends Mol Med 2007;13:460-469.

17. Kawai T, Adachi O, Ogawa T, Takeda K, Akira S. Unresponsiveness of MyD88-deficient mice to endotoxin. Immunity 1999;11:115-122.

18. Yamamoto M, Sato S, Hemmi H, et al. Role of adaptor TRIF in the MyD88-independent toll-like receptor signaling pathway. Science 2003;301:640-643.

19. Molnarfi N, Prod'homme T, Schulze-Topphoff U, et al. Glatiramer acetate treatment negatively regulates type I interferon signaling. Neurol Neuroimmunol Neuroinflamm 2015;2: e179. doi: 10.1212/NXI.0000000000000179.

20. Matsushima GK, Morell P. The neurotoxicant, cuprizone, as a model to study demyelination and remyelination in the central nervous system. Brain Pathol 2001;11:107-116. 


\section{Neurology \\ Neuroimmunology \& Neuroinflammation}

\section{Laquinimod prevents cuprizone-induced demyelination independent of Toll-like receptor signaling \\ Nadine Kramann, Lena Menken, Liat Hayardeny, et al. \\ Neurol Neuroimmunol Neuroinflamm 2016;3; \\ DOI 10.1212/NXI.0000000000000233}

This information is current as of May 17, 2016

\section{Updated Information \& \\ Services}

References

Citations

Subspecialty Collections

Permissions \& Licensing

Reprints including high resolution figures, can be found at:

http://nn.neurology.org/content/3/3/e233.full.html

This article cites 20 articles, 1 of which you can access for free at: http://nn.neurology.org/content/3/3/e233.full.html\#\#ref-list-1

This article has been cited by 2 HighWire-hosted articles: http://nn.neurology.org/content/3/3/e233.full.html\#\#otherarticles

This article, along with others on similar topics, appears in the following collection(s):

Multiple sclerosis

http://nn.neurology.org//cgi/collection/multiple_sclerosis

Information about reproducing this article in parts (figures,tables) or in its entirety can be found online at:

http://nn.neurology.org/misc/about.xhtml\#permissions

Information about ordering reprints can be found online: http://nn.neurology.org/misc/addir.xhtml\#reprintsus

Neurol Neuroimmunol Neuroinflamm is an official journal of the American Academy of Neurology.

Published since April 2014, it is an open-access, online-only, continuous publication journal. Copyright $\odot$ 2016 American Academy of Neurology. All rights reserved. Online ISSN: 2332-7812.

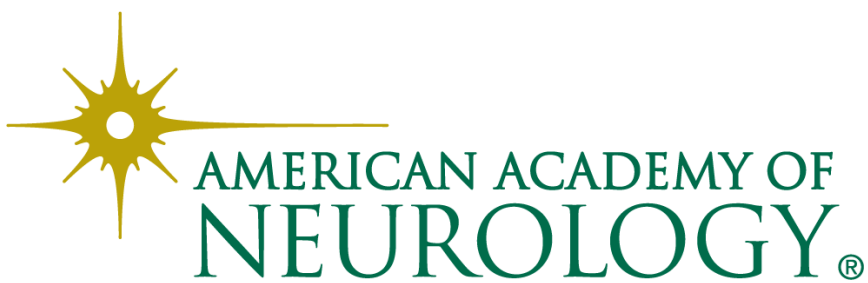

